\title{
Clarifications on the Design and Interpretation of Conclusions from Health Canada's Study on Wind Turbine Noise and Health
}

\author{
David S. Michaud ${ }^{1} \cdot$ Katya Feder $^{1} \cdot$ Sonia A. Voicescu ${ }^{1} \cdot$ Leonora Marro $^{2} \cdot$ John $^{\text {Than }}{ }^{2} \cdot$ Mireille Guay $^{2}$. \\ Eric Lavigne $^{3}$ - Allison Denning ${ }^{4} \cdot$ Brian J. Murray $^{5} \cdot$ Shelly K. Weiss ${ }^{6} \cdot$ Paul Villeneuve $^{7}$
}

Received: 1 August 2017 / Accepted: 28 December 2017 / Published online: 1 February 2018

(c) Crown in Right of Canada 2018. This article is an open access publication

\begin{abstract}
It has been extensively communicated that Health Canada's Community Noise and Health Study (CNHS) did not find positive associations between wind turbine noise (WTN) levels and any of the evaluated health outcomes, beyond an increase in the prevalence of high annoyance toward several wind turbine features. The authors emphasize that this general conclusion remains bound by the study strengths and limitations. Following the publication of the CNHS findings, there has been interest among some individuals to present alternative interpretations of the results originally reported by Michaud et al. (J Acoust Soc Am 139(3):1443-1454, 2016. https://doi.org/10.1121/1.4942391). While recognizing the importance of independent scientific re-evaluation and/or reinterpretation, this commentary serves to clarify and, where necessary, correct some of the information put forward by others. One factor that has been re-evaluated by external stakeholders is the subsample of participants that comprise the lowest WTN category. In their reanalysis, they have eliminated this category, or introduced alternative comparative data. This paper identifies substantial issues associated with the re-evaluation put forth. To thoroughly address these issues and to avoid further confusion or misinterpretation, the authors of the CNHS provide a comparison between the CNHS health condition prevalence data and nationally representative health-based surveys conducted in Canada during the same calendar year. In addition, this paper responds to comments received to date on the CNHS, including the study's age range, the generalization of findings, the provision of raw data, and conclusions on the association between WTN level and health.
\end{abstract}

Keywords Canada $\cdot$ Community Noise and Health Study $\cdot$ Wind turbine $\cdot$ Noise $\cdot$ Health effects $\cdot$ Cross-sectional study

David S. Michaud

david.michaud@canada.ca

1 Environmental and Radiation Health Sciences Directorate, Consumer and Clinical Radiation Protection Bureau, Health Canada, 775 Brookfield Road, Ottawa, ON K1A 1C1, Canada

2 Population Studies Division, Biostatistics Section, Health Canada, 101 Tunney's Pasture Driveway, Tunney's Pasture, Ottawa, ON, Canada

3 Air Health Science Division, Health Canada, 269 Laurier Avenue West, Ottawa, ON, Canada

4 Environmental Health Program, Regulatory Operations and Regions Branch, Health Canada, 1505 Barrington Street, Halifax, NS, Canada

5 Department of Medicine, Division of Neurology, Sunnybrook Health Sciences Center, University of Toronto, Toronto, ON, Canada

\section{Background}

From 2012-2014, Health Canada, in collaboration with Statistics Canada and other external experts conducted a cross-sectional study to investigate the relationship between exposure to sound levels produced from wind turbines and the extent of health effects reported by, and objectively measured in individuals living near wind turbines. In March 2016, the study findings from Health Canada's Community Noise and Health Study (CNHS) were published in the Journal of the Acoustical Society of America as a special section on wind turbine noise (WTN) [1-6]. These papers followed the

6 Department of Pediatrics, Division of Neurology, Hospital for Sick Children, University of Toronto, 555 University Avenue, Toronto, ON, Canada

7 Department of Health Sciences, Carleton University, Ottawa, ON, Canada 
CNHS's publications related to quality of life [7] and sleep [8].

The study design was subjected to a rigorous peer review process, which included a 60-day public consultation, a Research Ethics Board review, a review by Health Canada's Science Advisory Board, a review by external experts selected by the World Health Organization (WHO), and the publication of the final planned study design [9]. Publications also reflect the assessment conducted as part of the independent journal review process. Discussions during the study design phase included the selection of a "control group" (i.e., individuals who would have no meaningful exposure to WTN). In any epidemiological study, a control group is always a challenge to establish because it is exceedingly difficult to ensure that the only distinction between the control and exposed group is the exposure of interest; in this case, WTN. In the CNHS, it was determined before the study was conducted that an exposureresponse design would be implemented. Inherent to the exposure-response design is that participants are primarily distinguished by the magnitude of their exposure to WTN. Random sampling across different WTN categories strengthens the validity of the exposure-response insofar as it minimizes the likelihood that participant differences will bias the response to WTN at any given exposure level. With this study design participants in the lowest WTN exposure group (i.e., $<25 \mathrm{dBA}$ ) can be viewed as a control or comparison group, even though a true control group is more readily established under structured laboratory conditions.

The entire sample was drawn from areas in Prince Edward Island (PEI) and Ontario with similar topography, trees, hills, bodies of water, climate and socioeconomic characteristics. Exposure to WTN levels ranged from $<25$ to $46 \mathrm{dBA}$ and the distance between dwellings and turbines was between 0.25 and $11.22 \mathrm{~km}$. The study design included over-sampling in areas where WTN levels were highest to increase the statistical power for detecting potential WTN-associated effects on sleep quality. This over-sampling was also intended to better characterize the exposure-response relationship between WTN levels and various self-reported and objectively measured outcomes in areas where potential health impacts were more likely to be observed. As shown in Michaud et al. [1], reproduced as Table 1, participants in the lowest WTN exposure category had similar demographics compared to participants in other WTN categories. Demographically, some minor differences were found with respect to age, employment, type of dwelling and dwelling ownership; however, with the possible exception of employment, these factors showed no obvious pattern with WTN levels and none were strong enough to exert an influence on the overall results. The primary distinction across the study sample, based on the data collected, was the participants' exposure to WTN.

\section{Study Strengths and Limitations}

The strengths of the CNHS are as follows: (1) large randomly selected sample of participants $(n=1238),(2)$ high response rate $(78.9 \%)$ that did not vary by proximity to wind turbines in either province, (3) broadly scoped questionnaire, (4) inclusion of objectively measured endpoints of stress, blood pressure, heart rate and sleep, (5) calculated WTN levels validated with representative field measures, and (6) an exposure-response analysis that encompassed a greater than $21 \mathrm{~dB}$ range of exposure to WTN. Despite these strengths, no single cross-sectional study should be viewed as conclusive, and all studies have some limitations. As part of the external peer review of the current publication, it has been noted that the objectively measured outcomes included are not without their own shortcomings. This comment has merit insofar as no single observation should be interpreted in isolation, whether self-reported or objectively measured. Although each objective measure can be criticized in isolation as imperfect, there is added assurance of their validity insofar as they were found to be consistently related to their corresponding self-reported measures. Selfreported high blood pressure was related to higher measured blood pressure, higher perceived stress scores were related to higher hair cortisol concentrations and a lack of an association between WTN levels and reported sleep disturbance (for any reason) was consistent with sleep actigraphy findings.

Cross-sectional studies are a useful and powerful epidemiological tool used to evaluate issues related to public health. However, they are observational studies that collect data at a specific point in time and as such they are typically limited for making causal inferences. Furthermore, they rarely have the statistical power to characterize associations between exposures under study and health conditions that may have very low prevalence rates. Conclusions from the CNHS do not necessarily extrapolate beyond the study sample because the communities in the study may have important differences when compared to others in Canada, or elsewhere. Similarly, the findings are representative only of areas where long-term outdoor WTN levels do not exceed $46 \mathrm{dBA}$ (or $63 \mathrm{dBC}$ ) [4,5] and for individuals between the ages of 18 and 79 years. It should be acknowledged that long-term WTN calculations do not investigate specific noise characteristics, such as amplitude modulation and/or the presence of tones and are insensitive to very brief changes in WTN levels. Despite the fact that participants in the study were randomly selected, the locations were not and for this reason the level of confidence for generalizing the results to other areas can only be based on a scientific judgment regarding the level of exposure, terrain, climate, meteorology, and the similarity between the current study sample and others. These study limitations have been identified previously [10]. Thus, similar to epidemiological studies conducted in other areas, this study should be viewed 
Table 1 Study sample characteristics reported in Health Canada's Community Noise and Health Study

\begin{tabular}{|c|c|c|c|c|c|c|c|}
\hline \multirow[t]{2}{*}{ Variable } & \multicolumn{7}{|l|}{ WTN (dBA) } \\
\hline & $<25$ & {$[25-30)$} & {$[30-35)$} & {$[35-40)$} & {$[40-46]$} & Overall & $\mathrm{CMH} p$ value $^{\mathrm{a}}$ \\
\hline$n$ & $84^{\mathrm{b}}$ & $95^{\mathrm{b}}$ & $304^{\mathrm{b}}$ & $521^{\mathrm{b}}$ & $234^{\mathrm{b}}$ & $1238^{\mathrm{b}}$ & \\
\hline Range of closest turbine $(\mathrm{km})$ & $2.32-11.22$ & $1.29-4.47$ & $0.73-2.69$ & $0.44-1.56$ & $0.25-1.05$ & & \\
\hline Range of BNTS (dBA) & $35-51$ & $35-51$ & $35-56$ & $35-57$ & $35-61$ & & \\
\hline BNTS (dBA) mean (SD) & $43.88(3.43)$ & $44.68(2.91)$ & $45.21(3.60)$ & $43.29(4.11)$ & $41.43(4.21)$ & & \\
\hline $\mathrm{ON}$ & $44.98(2.88)$ & $44.86(2.78)$ & $45.54(3.31)$ & $44.06(3.86)$ & $42.70(4.25)$ & & $<0.0001^{\mathrm{c}}$ \\
\hline PEI & $41.13(3.18)$ & $43.00(3.67)$ & $43.81(4.38)$ & $38.44(1.59)$ & $38.05(1.00)$ & & $<0.0001^{\mathrm{c}}$ \\
\hline Sex $n(\%$ male $)$ & $37(44.0)$ & $48(50.5)$ & $150(49.3)$ & $251(48.2)$ & $120(51.3)$ & $606(49.0)$ & 0.4554 \\
\hline Age mean (SE) & $49.75(1.78)$ & $56.38(1.37)$ & $52.25(0.93)$ & $51.26(0.68)$ & $50.28(1.03)$ & $51.61(0.44)$ & $0.0243^{\mathrm{d}}$ \\
\hline Marital status $n(\%)$ & & & & & & & 0.2844 \\
\hline Married/common-law & $54(64.3)$ & $69(73.4)$ & $199(65.7)$ & $367(70.6)$ & $159(67.9)$ & $848(68.7)$ & \\
\hline Widowed/separated/divorced & $16(19.0)$ & $18(19.1)$ & $61(20.1)$ & $85(16.3)$ & $35(15.0)$ & $215(17.4)$ & \\
\hline Single, never been married & $14(16.7)$ & $7(7.4)$ & $43(14.2)$ & $68(13.1)$ & $40(17.1)$ & $172(13.9)$ & \\
\hline Employed $n(\%)$ & $43(51.8)$ & $47(49.5)$ & $161(53.0)$ & $323(62.0)$ & $148(63.2)$ & $722(58.4)$ & 0.0012 \\
\hline Level of education $n(\%)$ & & & & & & & 0.7221 \\
\hline$\leq$ High school & $45(53.6)$ & $52(54.7)$ & $167(55.1)$ & $280(53.7)$ & $134(57.3)$ & $678(54.8)$ & \\
\hline Trade/certificate/college & $34(40.5)$ & $37(38.9)$ & $110(36.3)$ & $203(39.0)$ & $85(36.3)$ & 469 (37.9) & \\
\hline University & $5(6.0)$ & $6(6.3)$ & $26(8.6)$ & $38(7.3)$ & $15(6.4)$ & $90(7.3)$ & \\
\hline Income $(\mathrm{x} \$ 1000) n(\%)$ & & & & & & & 0.8031 \\
\hline$<60$ & $39(51.3)$ & $40(54.8)$ & $138(52.5)$ & $214(49.1)$ & $100(49.3)$ & $531(50.5)$ & \\
\hline $60-100$ & $18(23.7)$ & $17(23.3)$ & $72(27.4)$ & $134(30.7)$ & $59(29.1)$ & $300(28.5)$ & \\
\hline$\geq 100$ & $19(25.0)$ & $16(21.9)$ & $53(20.2)$ & $88(20.2)$ & $44(21.7)$ & $220(20.9)$ & \\
\hline Detached dwelling $n(\%)^{\mathrm{e}}$ & $59(70.2)$ & $84(88.4)$ & $267(87.8)$ & $506(97.1)$ & $216(92.3)$ & $1132(91.4)$ & \\
\hline $\mathrm{ON}^{\mathrm{e}}$ & $46(76.7)$ & $77(89.5)$ & $228(93.1)$ & $437(97.1)$ & $154(90.6)$ & $942(93.2)$ & $<0.0001^{\mathrm{f}}$ \\
\hline $\mathrm{PEI}^{\mathrm{e}}$ & $13(54.2)$ & 7 (77.8) & $39(66.1)$ & $69(97.2)$ & $62(96.9)$ & $190(83.7)$ & $<0.0001^{\mathrm{f}}$ \\
\hline Property ownership $n(\%)$ & $60(71.4)$ & $85(89.5)$ & $250(82.2)$ & $466(89.4)$ & 215 (91.9) & $1076(86.9)$ & \\
\hline ON & $45(75.0)$ & $78(90.7)$ & $215(87.8)$ & $399(88.7)$ & $157(92.4)$ & $894(88.4)$ & $0.0085^{f}$ \\
\hline PEI & $15(62.5)$ & 7 (77.8) & $35(59.3)$ & 67 (94.4) & 58 (90.6) & $182(80.2)$ & $<0.0001^{\mathrm{f}}$ \\
\hline Façade type $n(\%)$ & & & & & & & 0.0137 \\
\hline Fully bricked & $20(23.8)$ & $30(31.6)$ & $85(28.0)$ & $138(26.5)$ & 67 (28.6) & $340(27.5)$ & \\
\hline Partially bricked & 24 (28.6) & $29(30.5)$ & $62(20.4)$ & $88(16.9)$ & $15(6.4)$ & $218(17.6)$ & \\
\hline No brick/other & $40(47.6)$ & $36(37.9)$ & $157(51.6)$ & $295(56.6)$ & $152(65.0)$ & $680(54.9)$ & \\
\hline
\end{tabular}

Originally presented as Table III in reference [1]

$B N T S$ Background nighttime sound level; $d B A$ A-weighted decibel; $k m$ kilometer; $O N$ Ontario, PEI Prince Edward Island; SD standard deviation; $S E$ standard error; $W T N$ wind turbine noise

${ }^{a}$ The Cochran-Mantel-Haenszel (CMH) chi-square test is used to adjust for province unless otherwise indicated, $p$ values $<0.05$ are considered to be statistically significant

$\mathrm{b}$ Totals may differ due to missing data

c Analysis of variance (ANOVA) model

${ }^{\mathrm{d}}$ Non-parametric two-way ANOVA model adjusted for province

e Non-detached dwellings included semi/duplex/apartment

${ }^{\mathrm{f}}$ Chi-square test of independence

with its numerous strengths and limitations in mind, in context of other similarly well conducted studies as well as what is known with respect to biologically plausible mechanisms.

Bearing in mind the stated strengths and limitations of the CNHS, the CNHS data support the general conclusion that beyond an increase in the prevalence of long-term high annoyance toward several wind turbine features [1], there was no evidence to support an association between WTN levels up to $46 \mathrm{dBA}$ and any of the other self-reported or objectively measured health outcomes. Reported and measured health 
outcomes included, but were not limited to, migraines, dizziness, tinnitus, blood pressure, heart disease, stress, quality of life and multiple measures of sleep $[1,3,7,8]$. Conclusions based on objectively measured outcomes for measures of stress, blood pressure/heart rate and sleep have additional credibility insofar as they are not influenced by participant awareness bias, which is always something that researchers need to consider when relying solely on self-reported measures of health.

\section{Clarifications in Response to CNHS Criticisms and Misinterpretations}

Constructive criticism of scientific research is encouraged because it often stimulates improvements in future studies. Some of the points of criticism put forward to challenge the conclusions of the CNHS relate to issues already documented by Health Canada as part of the acknowledged study strengths and limitations (see above). Other misinterpretations of the CNHS findings have resulted from selective reanalysis of some of the self-reported health data by external stakeholders. The issues discussed below have been noted either through discussions between individuals and the CNHS principal investigator (DSM) at scientific conferences and/or in feedback submitted directly to Health Canada. The CNHS authors' response to each of these criticisms (summarized in bold) is presented below.

\subsection{The CNHS is Flawed Because of Age Exclusions}

A primary objective of the study was to assess the potential impacts that WTN had on measured sleep. For this reason, the study design aimed to maximize the number of participants that fell within the age range studied most frequently by other researchers in this area, and in other community noise and sleep studies published to date. This approach would be expected to increase the statistical power of the CNHS to detect changes in sleep, should they exist. Sleep patterns among children and the elderly are sufficiently different from the study sample age group that their inclusion may have diluted the ability to detect subtle impacts on sleep from WTN exposure [11]. Furthermore, the questionnaire in the study included questions that would not be suitable for minors. Participants above the age of 79 years were also excluded, in part, because age-related hearing loss may influence their perception of WTN, and they are more likely to have other comorbid conditions that impact sleep. Ultimately, the study sample was limited to the age categories investigated by other researchers in this area in order to maximize the possibility of identifying impacts on sleep and other health outcomes, should they exist.

\subsection{Data from the CNHS Have Not Been Provided to the Public}

In support of transparency and scientific integrity, data originating from the study are available to Canadians, other jurisdictions and interested parties through a number of sources that include the Statistics Canada Research Data Centres [12], and by request through the Health Canada Wind Turbine Noise webpage (additional information) [13]. All publications are freely available as open access in scientific journals, and as plain language summaries on Health Canada's Web site [13]. All data that would be required to reproduce the CNHS findings are available through the means identified above. Data that contain information that could either be used to reveal the identity of a study participant or considered to be confidential business information is not provided, consistent with requirements/exclusions under Canada's Statistics Act and Privacy Act. Acoustical field recordings made to support WTN calculations are not provided to the public as they contain personal conversations which due to the length of the recordings (over 4000 hours) cannot be redacted.

\subsection{The CNHS Did Not Adequately Investigate People Who Have Abandoned Their Homes Due to Health Effects Suffered Following the Installation of Wind Turbines}

This is one of the more common assertions by external stakeholders, which is, at least in part, due to the imprecise terminology originally used to describe addresses that were not valid dwellings and therefore considered out-ofscope. The number of addresses considered out-of-scope for the sample was consistent with numbers predicted by Statistics Canada for a rural environment in Canada. Of the 434 out-of-scope addresses, 132 of these were identified as unoccupied for unknown reasons and were found to be randomly distributed across all distances studied in both provinces. Health Canada has no way of knowing the reasons for such vacancies. As specified in Michaud et al. [1] locations coded as out-of-scope were originally [14] assigned the following categories: Demolished for unknown reasons, vacant for unknown reasons, unoccupied, seasonal, $>79$ years of age, and other. In an effort to address feedback and provide further clarification, the categories used to define these addresses have been more precisely defined in [1]. Specifically, locations that were originally defined broadly as "unoccupied for unknown reasons" are now more precisely defined as 1) inhabitable dwelling not occupied at time of survey, 2) newly constructed dwelling, but not yet inhabited, or 3) unoccupied trailer in vacant trailer park. Furthermore, it was confirmed that 6 addresses originally identified as unoccupied were in fact GPS coordinates listed in error [1]. There 
was no evidence in the study to support the suggestion that the unoccupied dwellings have been abandoned by homeowners suffering adverse health effects from WTN exposure.

\subsection{Despite an Increase in Annoyance, the CNHS Concluded No Adverse Health Effects}

No evidence was found that would reject the null hypothesis; in essence, there was no association between exposure to WTN and the self-reported or objectively measured health endpoints examined. However, the study did demonstrate a relationship between increasing levels of WTN and annoyance toward several features (including noise, perceived indoor vibration during operations, ${ }^{1}$ visual impacts, shadow flicker, and the aircraft warning lights on top of the turbines) associated with wind turbines. The WHO Community Noise Guidelines list annoyance as one of the adverse health effects of community noise exposure and include guidelines for annoyance that vary in level based on location and time of day [15]. In their estimation of the burden of disease from environmental noise exposure, the WHO regional office for Europe has assigned a "conservative" disability weight of 0.02 to long-term high (transportation) noise annoyance, where 0 is equivalent to ideal health and 1 is equivalent to death [16]. Although a statistical association was found between high WTN annoyance and several reported and measured health endpoints in the CNHS, these were unrelated to the level of WTN exposure, and there is no way of determining if these conditions may have either pre-dated, and/or were possibly exacerbated by, exposure to wind turbines [1$3,7]$. The extent to which long-term high noise annoyance may impact one's health is uncertain. To illustrate, a national Canadian survey on road traffic noise annoyance where 2565 respondents rated their level of annoyance toward road traffic noise over the previous year is highlighted. In the latter study, respondents assessed on an 11-point numerical scale, where 0 was equivalent to "no effect" and 10 was equivalent to "very strong effect," the extent to which their annoyance toward road traffic noise was perceived to have a negative impact on their health. Among respondents who rated their annoyance toward road traffic noise as high, $39 \%$ perceived the impact of their annoyance on their health to be equivalent to 7 and above. On the other hand, only $6 \%$ of respondents who reported lower magnitudes of annoyance (i.e., moderate or lower), perceived the impact on their health as 7 and above. These observations imply a greater importance of "high" noise annoyance in comparison with lower magnitudes and

\footnotetext{
1 Vibrations/rattles during wind turbine operations were not directly measured or modeled in the CNHS. Michaud et al [1] reported that $4.7 \%$ of participants perceived vibrations/rattles during operations, and $1.5 \%$ reported to be highly annoyed by vibrations/rattles. Both the perception of and annoyance toward vibration/rattle were found to be statistically related to WTN level.
}

appear to suggest that approximately 2 in 5 Canadians highly annoyed by road traffic noise perceive their annoyance to have a rather strong impact on their health. However, the same survey also demonstrated that annoyance magnitude was not correlated with self-reported health status, that is, many who reported to be highly annoyed by road traffic noise also reported to be in good health [17]. Thus there are inconsistent findings between long-term noise annoyance and potential impacts on health. Considering the comparatively low magnitude of the aforementioned disability weight while noting the observations that high noise annoyance has been reported to be associated with other health conditions $[16,18,19]$ support an interpretation of high noise annoyance as a potential, but not a necessary or distinct indicator of adverse health. Collectively, these observations may support decisions by jurisdictions to consider changes in the prevalence of community annoyance when evaluating wind turbine installation projects.

\subsection{The Prevalence of Health Effects in the Lowest WTN Category Were Inflated}

Following publication of CNHS findings, there has been interest among some individuals not involved in the original CNHS, to reassess a sub-selection of the reported health effects. The CNHS authors recognize the importance of independent scientific re-evaluation and/or reinterpretation however, emphasize caution when reinterpreting results that have been derived through selective removal of data and statistically questionable methodologies. One such reanalysis involved the removal of participants from areas where WTN levels were below $25 \mathrm{dBA}$ based on a concern that the prevalence rates for certain health outcomes (i.e., tinnitus, migraines, dizziness and relative health status compared to last year) were inflated and non-representative [20,21].

An alternative comparison group was comprised for one such reanalysis that included multiple data sources from the $\mathrm{USA}^{2}$ in addition to sources from a study conducted in a city within the province of Ontario $(n=671)$. The Ontario data were collected in 2001 and 2003 with the purpose of assessing how self-reported health changed over time when the same individuals were evaluated in both surveys [22]. Collectively, these multiple data sources have been mistakenly interpreted and presented to reflect "General Population Prevalence" data. The scientific rationale for removing the

\footnotetext{
2 USA data sources included Migraine Research Foundation, which reports $12 \%$ of the population suffers from migraine; however, this statistic appears to include children, who were excluded from the CNHS. The same Web site indicated that 1 in 4 (or 25\%) of U.S. households included an individual with migraine. Other cited USA sources include Dizziness-and-balance.com, and Hearing Health Foundation, where the latter source reports that $10 \%$ of the USA adult population experienced tinnitus over the last 3 months.
} 
prevalence data observed in the lowest WTN exposure category and then re-evaluating the recompiled data is tenuous given, in part, that they were derived at different time periods for different years (almost a decade earlier) and/or nations. Furthermore, the selective reanalysis of only tinnitus, dizziness, migraines and relative health status compared to 1 year earlier is inconsistent with assertions that WTN exposure adversely impacts a wide range of outcomes including, but not limited to sleep, stress and anxiety, cardiovascular responses and quality of life; all of which were among the 20 health conditions evaluated in the CNHS, reproduced in Table 2.

Several factors can reduce scientific validity when making comparisons with historical data from different studies. There may be little scientific support for comparisons between self-reported data that are collected in different study populations especially when the collection periods are separated by several years. A more serious deterrent to such comparisons arises where there are important differences between study methodologies (e.g., data collection, questionnaire content), which can lead to erroneous comparisons, even when the endpoints assessed are similar. For example, there is a clear distinction between a question that evaluates the current status of migraines or tinnitus and one that seeks to determine if these conditions were ever experienced in one's lifetime. Similarly, the prevalence of a self-reported health condition is not equivalent to the prevalence of consulting with a health-care professional for the same condition. Table 3 illustrates this difference for migraines, dizziness and tinnitus, as reported in the CNHS. Studies like the CNHS, that investigate the potential association between an environmental exposure and health, are especially sensitive to the possibility that publicity regarding health impacts may influence participant response (i.e., awareness bias). Strategies to mitigate this bias in the CNHS included masking the study objective during recruitment, random sampling, a high response rate and supplementing self-report with objective measures. Nevertheless, awareness bias can never be fully eliminated and is another factor to consider when comparing study findings that may be distorted by this bias to varying degrees. No attempt was made to ensure the CNHS was representative of a larger population as doing so is not necessary to ensure a reliable cross-sectional study. Therefore, one must avoid potential "apples to oranges" comparisons as the sample population in the CNHS is not generalizable. This has been identified by the CNHS authors as one of the limitations (i.e., caution on extrapolation beyond the study sample because the communities in the study may have important differences when compared to others in Canada, or elsewhere). With these considerations in mind, this paper presents an opportunity to make some careful comparisons between the CNHS and larger population-based studies that were conducted in Canada during the same calendar year as the CNHS. These comparisons may be of interest to persons reviewing the prevalence data published as part of the CNHS [1].

The Canadian Community Health Survey (CCHS $)^{3}$ and the Canadian Health Measures Survey (CHMS) ${ }^{4}$ [23,24] are two large-scale population-based surveys routinely conducted by Statistics Canada to collect nationally representative health data on Canadians. These studies are weighted to account for the distribution of Canadians by sex and age. These surveys do not claim to be representative of any particular sub-community. Individual communities may have important differences in the sample characteristics (e.g., health status, socioeconomic variables), which can influence the reported prevalence rates. Response rates for the CCHS and CHMS tend to be lower than that observed in the CNHS (i.e., 78.9\%) and therefore caution should be exercised in comparing these larger surveys with the CNHS, which is more appropriately referred to as a community study and not a national survey. Table 3 provides comparisons between these larger studies and the CNHS on self-reported measures of health. Potentially important differences were noted between questionnaire content (Table 4), which should be factored into the interpretation of study differences. To our knowledge, the prevalence of dizziness has not been assessed in any nationally representative Canadian survey. Reported prevalence rates vary considerably depending on the type of dizziness evaluated, participant sex and age [25]. Indeed, several health effects are known to increase in prevalence with age. Since the average age in the CNHS was higher than the CCHS and CHMS, differences in overall prevalence rates could potentially reflect age differences. For this reason, results are stratified by age category in Table 3 .

Finally, it should be underscored that the comparison of prevalence rates across exposure categories within any given study should consider the sample size for each exposure category. The Cochran-Mantel-Haenszel (CMH) test used in Michaud et al. [1] is a test used in the analysis of stratified categorical data. It allows an investigator to test the association between a categorical predictor or treatment and a binary outcome such as case or control status while taking into account the stratification of the study [26]. The test accounts for the variability or variance associated with each

\footnotetext{
3 The Canadian Community Health Survey (CCHS) is a cross-sectional survey conducted by Statistics Canada to gather health-related data at the sub-provincial levels of geography. The CCHS relies on a large sample $(65,000)$ to provide reliable health-related data every 2 years. The CCHS produces an annual microdata file and a file combining two years of data [23].

4 The Canadian Health Measures Survey (CHMS) is a survey conducted by Statistics Canada with the objective of collecting information on Canadians' health. The CHMS includes an in-home interview and a collection of physical measures on a wide range of outcomes, including blood pressure, height, weight, bone density, hearing, and vision. The sample size of each cycle of the CHMS is approximately 5700 [24].
} 
Table 2 Distribution of health conditions reported in Health Canada's Community Noise and Health Study

\begin{tabular}{|c|c|c|c|c|c|c|c|}
\hline \multirow{2}{*}{ Variable $n(\%)$} & \multicolumn{7}{|c|}{ WTN (dBA) } \\
\hline & $<25$ & {$[25-30)$} & {$[30-35)$} & {$[35-40)$} & {$[40-46]$} & Overall & $\mathrm{CMH}^{\mathrm{a}} p$ value \\
\hline$n$ & $84^{\mathrm{b}}$ & $95^{\mathrm{b}}$ & $304^{\mathrm{b}}$ & $521^{\mathrm{b}}$ & $234^{\mathrm{b}}$ & $1238^{\mathrm{b}}$ & \\
\hline Health worse versus last year ${ }^{c}$ & $17(20.2)$ & $12(12.6)$ & $46(15.1)$ & $90(17.3)$ & $51(21.8)$ & $216(17.5)$ & 0.1724 \\
\hline Migraines & $18(21.4)$ & $24(25.3)$ & $56(18.4)$ & $134(25.8)$ & $57(24.4)$ & $289(23.4)$ & 0.2308 \\
\hline Dizziness & $19(22.6)$ & $16(16.8)$ & $65(21.4)$ & $114(21.9)$ & $59(25.2)$ & $273(22.1)$ & 0.2575 \\
\hline Tinnitus & $21(25.0)$ & $18(18.9)$ & $71(23.4)$ & $129(24.8)$ & $54(23.2)$ & $293(23.7)$ & 0.7352 \\
\hline Chronic pain & $20(23.8)$ & $23(24.2)$ & $75(24.8)$ & $118(22.6)$ & $57(24.5)$ & $293(23.7)$ & 0.8999 \\
\hline Asthma & $8(9.5)$ & $12(12.6)$ & $22(7.2)$ & $43(8.3)$ & $16(6.8)$ & $101(8.2)$ & 0.2436 \\
\hline Arthritis & $23(27.4)$ & $38(40.0)$ & $98(32.2)$ & $175(33.7)$ & $68(29.1)$ & $402(32.5)$ & 0.6397 \\
\hline High blood pressure (BP) & $24(28.6)$ & $36(37.9)$ & $81(26.8)$ & $166(32.0)$ & $65(27.8)$ & $372(30.2)$ & 0.7385 \\
\hline Medication for high BP & $26(31.3)$ & $34(35.8)$ & $84(27.6)$ & $163(31.3)$ & $63(27.0)$ & $370(29.9)$ & 0.4250 \\
\hline Family history of high BP & $44(52.4)$ & $49(53.8)$ & $132(45.5)$ & $254(50.6)$ & $121(53.8)$ & $600(50.3)$ & 0.6015 \\
\hline Chronic bronchitis/emphysema/COPD & $3(3.6)$ & $10(10.8)$ & $17(5.6)$ & $27(5.2)$ & $14(6.0)$ & $71(5.7)$ & 0.7676 \\
\hline Diabetes & $7(8.3)$ & $8(8.4)$ & $33(10.9)$ & $46(8.8)$ & $19(8.2)$ & $113(9.1)$ & 0.6890 \\
\hline Heart disease & $8(9.5)$ & $7(7.4)$ & $31(10.2)$ & $32(6.1)$ & $17(7.3)$ & $95(7.7)$ & 0.2110 \\
\hline Highly sleep disturbed ${ }^{d}$ & $13(15.7)$ & $11(11.6)$ & $41(13.5)$ & $75(14.5)$ & $24(10.3)$ & $164(13.3)$ & 0.4300 \\
\hline Diagnosed sleep disorder & $13(15.5)$ & $10(10.5)$ & $27(8.9)$ & $44(8.4)$ & $25(10.7)$ & $119(9.6)$ & 0.3102 \\
\hline Sleep medication & $16(19.0)$ & $18(18.9)$ & $39(12.8)$ & $46(8.8)$ & $29(12.4)$ & $148(12.0)$ & 0.0083 \\
\hline Restless leg syndrome & $7(8.3)$ & $16(16.8)$ & $37(12.2)$ & $81(15.5)$ & $33(14.1)$ & $174(14.1)$ & \\
\hline Restless leg syndrome (ON) & $4(6.7)$ & $15(17.4)$ & $27(11.0)$ & $78(17.3)$ & $28(16.5)$ & $152(15.0)$ & $0.0629^{\mathrm{e}}$ \\
\hline Restless leg syndrome (PEI) & $3(12.5)$ & $1(11.1)$ & $10(16.9)$ & $3(4.2)$ & $5(7.8)$ & $22(9.7)$ & $0.1628^{\mathrm{e}}$ \\
\hline Medication anxiety or depression & $11(13.1)$ & $14(14.7)$ & $35(11.5)$ & $59(11.3)$ & $23(9.8)$ & $142(11.5)$ & 0.2470 \\
\hline \multicolumn{8}{|l|}{ QoL past month ${ }^{\mathrm{f}}$} \\
\hline Poor & $9(10.8)$ & $3(3.2)$ & $21(6.9)$ & $29(5.6)$ & $20(8.6)$ & $82(6.6)$ & 0.9814 \\
\hline Good & $74(89.2)$ & $92(96.8)$ & $283(93.1)$ & $492(94.4)$ & $213(91.4)$ & $1154(93.4)$ & \\
\hline \multicolumn{8}{|l|}{ Satisfaction with health ${ }^{\mathrm{f}}$} \\
\hline Dissatisfied & $13(15.5)$ & $13(13.7)$ & 49 (16.1) & $66(12.7)$ & $36(15.4)$ & $177(14.3)$ & 0.7262 \\
\hline Satisfied & $71(84.5)$ & $82(86.3)$ & $255(83.9)$ & $455(87.3)$ & $198(84.6)$ & $1061(85.7)$ & \\
\hline
\end{tabular}

Originally presented as Table $\mathrm{V}$ in reference [1]

$d B A$ A-weighted decibel; $C O P D$ chronic obstructive pulmonary disease; $O N$ Ontario, $P E I$ Prince Edward Island, WTN wind turbine noise

${ }^{a}$ The Cochran-Mantel-Haenszel (CMH) chi-square test is used to adjust for provinces unless otherwise indicated, $p$ values $<0.05$ are considered to be statistically significant

${ }^{\mathrm{b}}$ Columns may not add to total due to missing data

c Worse consists of the two ratings: "Somewhat worse now" and "Much worse now"

d High sleep disturbance consists of the two ratings: "very" and "extremely" sleep disturbed

e Chi-square test of independence

f Quality of Life (QoL) and Satisfaction with Health were assessed with the two stand-alone questions on the WHOQOL-BREF. Reporting "poor" overall QoL reflects a response of "poor" or "very poor", and "good" reflects a response of "neither poor nor good", "good" or "very good". Reporting "dissatisfied" overall Satisfaction with Health reflects a response of "very dissatisfied" or "dissatisfied", and "satisfied" reflects a response of "neither satisfied nor dissatisfied", "satisfied" or "very satisfied". A detailed presentation of the results related to QoL is presented by reference [7]

data point due to sample size within each WTN level category. Claims of a detectable trend in the data based solely on a linear regression line drawn through 4 data points are not supported as they do not reflect the variability (or precision) associated with each of these data points. This variability is related to the sample size in each of the WTN exposure categories and is a necessary statistical consideration when interpreting the CNHS data. Scientifically, the linear regression model used in [20] does not take into account sample sizes and the error is compounded by the elimination of participants from the lowest WTN exposure category. Furthermore, a simple regression line does not adjust for any confounding factors, an important consideration from an epidemiological point of view. For the reasons mentioned above, the CNHS authors agree with the State of Wisconsin's conclusion [27] that the analysis of the CNHS presented as part of the expert testimony in [20] was inappropriate and misleading. 


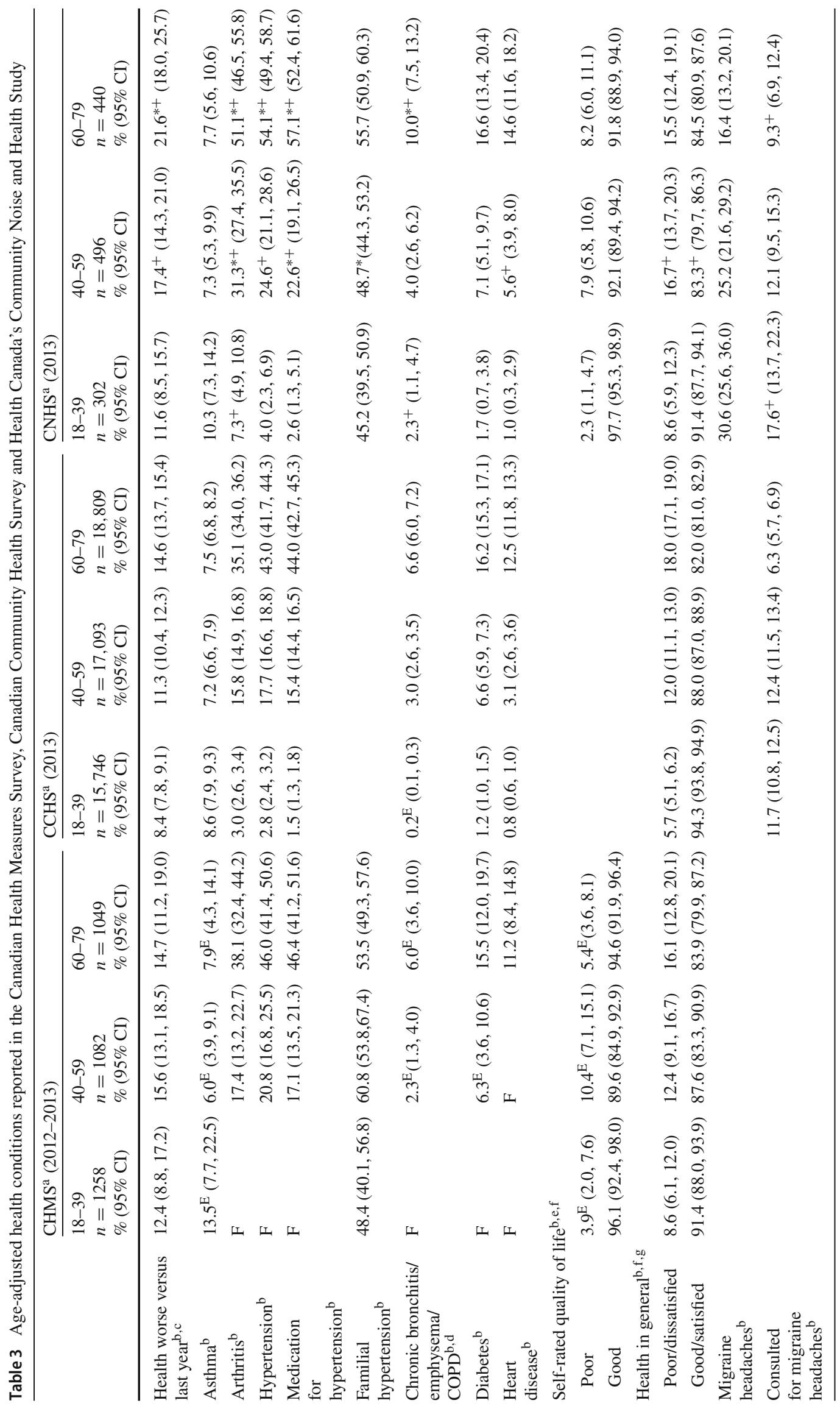




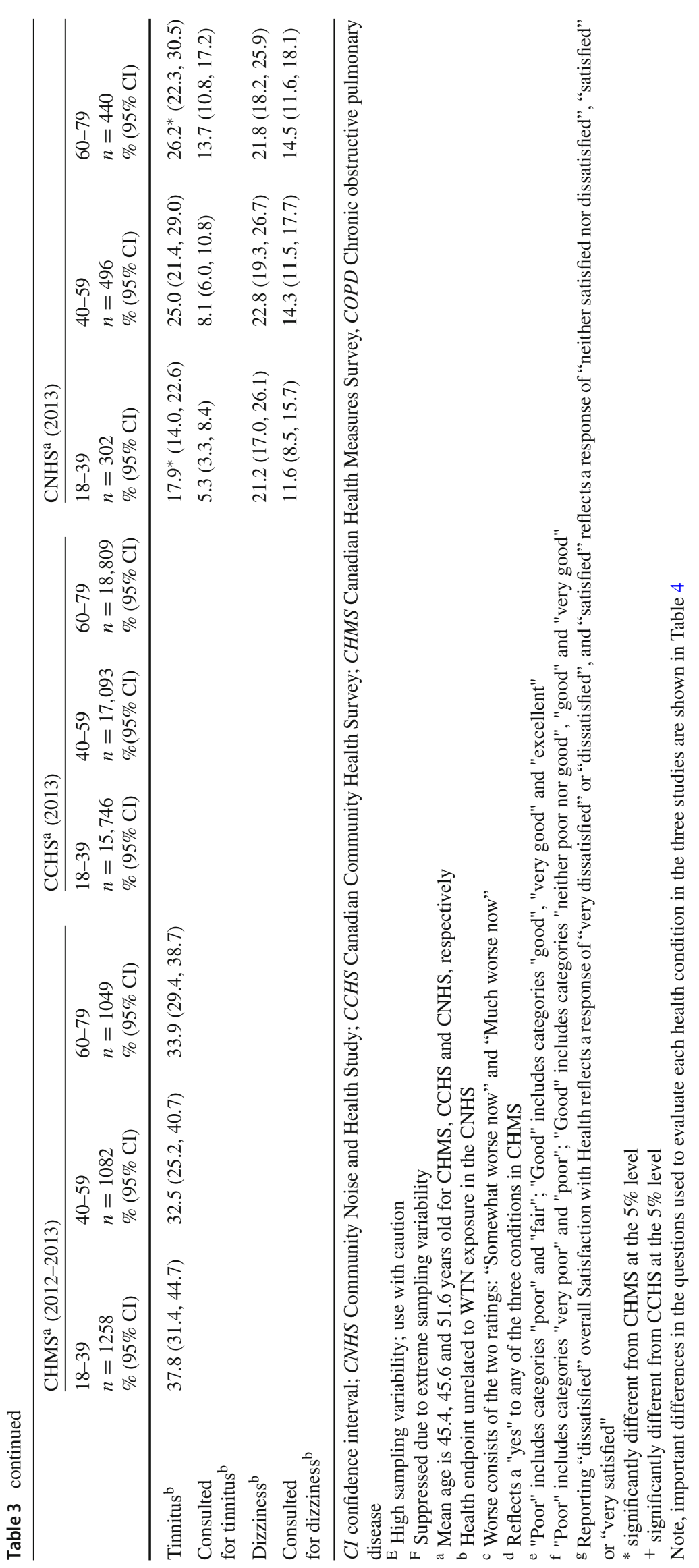


Table 4 Disparity between questions used to assess the same health conditions in the Canadian Health Measures Survey, Canadian Community Health Survey and Health Canada's Community Noise and Health Study

\begin{tabular}{ll}
\hline Health condition & CNHS question \\
\hline Health worse versus last year & Compared to one year ago, how would \\
& you say your health is now? Is it...? \\
& Much better now, Somewhat better \\
& now, About the same, Somewhat worse \\
& now, Much worse now
\end{tabular}

\begin{tabular}{|c|c|}
\hline Asthma $^{\mathrm{a}}$ & Do you have asthma? \\
\hline Arthritis $^{\mathrm{a}}$ & Do you have arthritis? \\
\hline Hypertension $^{\mathrm{a}}$ & Do you have high blood pressure? \\
\hline Medication for hypertension ${ }^{b}$ & $\begin{array}{l}\text { In the past month, have you taken any } \\
\text { medicine for high blood pressure? }\end{array}$ \\
\hline $\begin{array}{l}\text { Familial hypertension (risk } \\
\text { factor) }\end{array}$ & $\begin{array}{l}\text { Is there a history of high blood pressure } \\
\text { in your family? }\end{array}$ \\
\hline
\end{tabular}

Chronic bronchitis/ emphysema/COPD ${ }^{\text {ac }}$

\section{Diabetes $^{\mathrm{a}}$ \\ Heart disease ${ }^{\text {a }}$ \\ Self-rated quality of life}

Health in general

Migraine headaches ${ }^{\mathrm{d}, \mathrm{e}}$

Tinnitus $^{\mathrm{d}, \mathrm{f}}$

\section{Dizziness $^{\mathrm{d}}$}

Do you have chronic bronchitis, emphysema or chronic obstructive pulmonary disease?

\section{Do you have diabetes?}

Do you have heart disease?

In the past month, how would you rate your quality of life? Very poor, Poor, Neither poor nor good, Good, Very good

In the past month, how satisfied were you with your health? Very dissatisfied, Dissatisfied, Neither satisfied nor dissatisfied, Satisfied, Very Satisfied

In the last 12 months, have you experienced frequent migraines or headaches (includes nausea, vomiting, sensitivity to light and sound)?

In the last 12 months, have you experienced ringing, buzzing or whistling sounds in your ears for no reason?
Same question as CNHS

Same question as CNHS

Same question as CNHS

Same question as CNHS

Has anyone in your immediate family ever had high blood pressure, excluding during pregnancy?

Do you have chronic bronchitis? Do you have emphysema?

Do you have chronic obstructive pulmonary disease?

Same question as CNHS

Same question as CNHS

Would you rate your quality of life as...? Poor, Fair, Good, Very good, Excellent

In general, would you say your health is...? Poor, Fair, Good, Very good, Excellent

Not evaluated

Now I'd like to ask you about tinnitus. Tinnitus is the presence of hissing, buzzing, ringing, rushing or roaring sounds in your ears when there is no other sound around you. Have you ever experienced tinnitus?

Not evaluated

CCHS question

Same question as CNHS

Same question as CNHS

Do you have arthritis, excluding fibromyalgia?

Same question as CNHS

Same question as CNHS

Not evaluated

Same question as CNHS

Same question as CNHS

Same question as CNHS

Not evaluated

In general, would you say your health is...? Poor, Fair, Good, Very good, Excellent

Do you have migraine headaches?

Not evaluated

Not evaluated In the last 12 mo
enced dizziness?

CNHS Community Noise and Health Study; CCHS Canadian Community Health Survey; CHMS Canadian Health Measures Survey, COPD Chronic obstructive pulmonary disease

${ }^{a}$ In CNHS, CHMS and CCHS these questions are preceeded by : "We are interested in "long-term conditions" which are expected to last or have already lasted 6 months or more and that have been diagnosed by a health professional"

bIn CCHS, this question is skipped if the answer to high blood pressure is "no"

${ }^{\mathrm{c}}$ Question asked only if age $\geq 35$ in CCHS, and questions on emphysema and COPD if age $\geq 30$ in CHMS

${ }^{\mathrm{d}}$ In CNHS, if participants reported the condition, a follow-up question asked if they consulted with a health-care professional regarding the condition. Results originally reported by Michaud et al. [1] were for self-reported prevalence as only a subsample would be expected to consult with a health-care professional about the condition

${ }^{\mathrm{e}}$ In CCHS, response to question on migraines was preceeded with the following reminder by the interviewer: "Remember, we're interested in conditions diagnosed by a health professional and that are expected to last or have already lasted 6 months or more"

${ }^{\mathrm{f}}$ Tinnitus was evaluated in CHMS with response categories that permitted comparison to CNHS, i.e., experienced within the last year 


\section{Concluding Remarks}

No single study, regardless how comprehensive, can be expected to provide all of the answers to the many questions that exist in any given area of research and any study should be considered in the context of the broader evidence base. Knowledge gained through science is incremental, advanced through replication and consistency in observed outcomes from studies that employ different study designs and methods of exposure assessment. The CNHS results support an association between increasing WTN levels and an increase in the prevalence of annoyance toward various wind turbine features. As noted in the discussion of limitations, crosssectional studies are not sufficient to establish causality, yet they do have the strength of assessing multiple outcomes and exposures at the same time in large populations over short periods of time. For this reason, they often serve as the basis for hypothesis testing in follow-up case-control and cohort studies. The correlations that were observed between reported high WTN annoyance and some of the self-reported and measured health outcomes are not sufficient, in isolation, to suggest that high degrees of WTN annoyance cause these outcomes (or vice versa). These associations may be influenced by other risk factors that are unaccounted for in a single cross-sectional study, or by design biases (e.g., uses of self-reported data, participation bias). Should an association between high WTN annoyance and adverse health outcomes be established in the future, efforts to minimize annoyance be it from acoustical, or non-acoustical features (e.g., blinking light, shadow flicker mitigation) may be supported on those grounds.

The motivation behind the current commentary was to provide a formal response to feedback that has been received now that more than a year has passed since the primary research findings from the CNHS have been published. It also serves to identify several issues of concern around the reanalysis of the CNHS data presented as part of the expert testimony in [20]. Publishing in a special issue dedicated to WTN should broaden the reach of this response within the scientific community, highlighting important epidemiological principles that need to be considered when evaluating health studies. Our intention is that this commentary may serve as an acknowledgement of, and a collective response to, a range of issues that will undoubtedly remain relevant so long as the CNHS continues to inform discussions that surround the growing science base related to WTN exposure and human health.

Open Access This article is distributed under the terms of the Creative Commons Attribution 4.0 International License (http://creativecomm ons.org/licenses/by/4.0/), which permits unrestricted use, distribution, and reproduction in any medium, provided you give appropriate credit to the original author(s) and the source, provide a link to the Creative Commons license, and indicate if changes were made.

\section{References}

1. Michaud, D.S., Feder, K., Keith, S.E., Voicescu, S.A., Marro, L., Than, J., Guay, M., Denning, A., McGuire, D., Bower, T., Lavigne, E., Murray, B.J., Weiss, S.K., van den Berg, F.: Exposure to wind turbine noise: Perceptual responses and reported health effects. J. Acoust. Soc. Am. 139(3), 1443-1454 (2016). https://doi.org/10. $1121 / 1.4942391$

2. Michaud, D.S., Feder, K., Keith, S.E., Voicescu, S.A., Marro, L., Than, J., Guay, M., Bower, T., Denning, A., Lavigne, E., Whelan, C., Janssen, S.A., van den Berg, F.: Personal and situational variables associated with wind turbine noise annoyance. J. Acoust. Soc. Am. 139(3), 1455-1466 (2016). https://doi.org/10.1121/1. 4942390

3. Michaud, D.S., Feder, K., Keith, S.E., Voicescu, S.A., Marro, L., Than, J., Guay, M., Denning, A., Bower, T., Villeneuve, P., Russell, E., Koren, G., van den Berg, F.: Self-reported and measured stress related responses associated with exposure to wind turbine noise. J. Acoust. Soc. Am. 139(3), 1467-1497 (2016). https://doi.org/10. $1121 / 1.4942402$

4. Keith, S.E., Feder, K., Voicescu, S., Soukhovtsev, V., Denning, A., Tsang, J., Broner, N., Richarz, W., van den Berg, F.: Wind turbine sound power measurements. J. Acoust. Soc. Am. 139(3), 14311435 (2016). https://doi.org/10.1121/1.4942405

5. Keith, S.E., Feder, K., Voicescu, S., Soukhovtsev, V., Denning, A., Tsang, J., Broner, N., Richarz, W., van den Berg, F.: Wind turbine sound pressure level calculations at dwellings. J. Acoust. Soc. Am. 139(3), 1436-1442 (2016). https://doi.org/10.1121/1.4942404

6. Voicescu, S., Michaud, D.S., Feder, K., Marro, L., Than, J., Guay, M., Denning, A., Bower, T., van den Berg, F., Broner, N., Lavigne, E.: Estimating annoyance to calculated wind turbine shadow flicker is improved when variables associated with wind turbine noise exposure are considered. J. Acoust. Soc. Am. 139(3), 1480-1492 (2016). https://doi.org/10.1121/1.4942403

7. Feder, K., Michaud, D.S., Keith, S.E., Voicescu, S.A., Marro, L., Than, J., Guay, M., Denning, A., Bower, T.J., Lavigne, E., Whelan, C., van den Berg, F.: An assessment of quality of life using the WHOQOL-BREF among participants living in the vicinity of wind turbines. Environ. Res. 142, 227-238 (2015). https://doi.org/10. 1016/j.envres.2015.06.043

8. Michaud, D.S., Feder, K., Keith, S.E., Voicescu, S.A., Marro, L., Than, J., Guay, M., Denning, A., Murray, B.J., Weiss, S.K., Villeneuve, P.J., van den Berg, F., Bower, T.: Effects of wind turbine noise on self-reported and objective measures of sleep. SLEEP 39(1), 97-109 (2016). https://doi.org/10.5665/sleep.5326

9. Michaud, D.S., Keith, S.E., Feder, K., Soukhovtsev, V., Marro, L., Denning, A., McGuire, D., Broner, N., Richarz, W., Tsang, J., Legault, S., Poulin, D., Bryan, S., Duddeck, C., Lavigne, E., Villeneuve, P.J., Leroux, T., Weiss, S.K., Murray, B.J., Bower, T.: Self-reported and objectively measured health indicators among a sample of Canadians living within the vicinity of industrial wind turbines: Social survey and sound level modeling methodology. Noise News Int. 21, 14-27 (2013)

10. Health Canada: Health Impacts and Exposure to Sound From Wind Turbines: Updated Research Design and Sound Exposure Assessment. https://www.canada.ca/en/health-canada/services/ environmental-workplace-health/consultations/health-impactsexposure-sound-wind-turbines-updated-research-design-soundexposure-assessment.html (2014). Accessed 14 Nov 2017

11. Ohayon, M.M., Carskadon, M.A., Guilleminault, C., Vitiello, M.W.: Meta-analysis of quantitative sleep parameters from child- 
hood to old age in healthy individuals: developing normative sleep values across the human lifespan. SLEEP 27(7), 1255-1273 (2004). https://doi.org/10.1093/sleep/27.7.1255

12. Statistics Canada Research Data Centre reference. The Research Data Centres (RDC) Program. http://www.statcan.gc.ca/eng/rdc/ index (2017). Accessed 14 Nov 2017

13. Health Canada: Wind turbine noise. https://www.canada.ca/en/ health-canada/services/environmental-workplace-health/noise/ wind-turbine-noise.html (2014). Accessed 14 Nov 2017

14. Health Canada: Wind turbine Noise and Health Study: Summary of Results. https://www.canada.ca/en/health-canada/services/ environmental-workplace-health/noise/wind-turbine-noise/ wind-turbine-noise-health-study-summary-results.html (2014). Accessed 14 Nov 2017

15. World Health Organization: Guidelines for Community Noise. WHO, Geneva (1999)

16. World Health Organization (WHO): Burden of disease from environmental noise. Quantification of healthy life years lost in Europe. Fritschi, L., Brown, A.L., Kim, R., Schwela, D., Kephalopolous, S. (eds.). Bonn: World Health Organization, Regional Office for Europe (2011)

17. Michaud, D.S., Keith, S.E., McMurchy, D.: Annoyance and disturbance of daily activities from road traffic noise in Canada. J. Acoust. Soc. Am. 123(2), 784-792 (2008). https://doi.org/10. $1121 / 1.2821984$

18. Basner, M., Babisch, W., Davis, A., Brink, M., Clark, C., Janssen, S., Stansfeld, S.: Auditory and non-auditory effects of noise on health. Lancet 383(9925), 1325-1332 (2014). https://doi.org/10. 1016/S0140-6736(13)61613-X

19. Niemann, H., Bonnefoy, X., Braubach, M., Hecht, K., Maschke, C., Rodrigues, C., Röbbel, N.: Noise-induced annoyance and morbidity results from the pan-European LARES study. Noise Health 8(31), 63-79 (2006). http://www.noiseandhealth.org/text. asp?2006/8/31/63/33537

20. Public Service Commission of Wisconsin (PSCW): Application of Highland Wind Farm, LLC, for a certificate of public convenience and necessity to construct a $102.5 \mathrm{MW}$ wind electric generation facility and associated electric facilities, to be located in the towns of Forest and Cylon, St. Croix County, Wisconsin. Expert statement of Richard James. Docket No.: 2525-CE-100. http://apps.psc.wi.gov/vs2015/ERF_ view/viewdoc.aspx?docid=284895. Accessed 14 Nov 2017
21. Nissenbaum, M.A.: Industrial wind turbines and adverse health effects: where we are, where we need to go, and the need for regulations and predictive models to recognize human physiology. J. Acoust. Soc. Am. 139, 2149 (2016). https://doi.org/10.1121/1. 4950348

22. Wilson, K., Elliott, S.J., Eyles, J.D., Keller-Olaman, S.J.: Factors affecting change over time in self-reported health. Can. J. Public Health 98(2) 154-158 (2007). https://www.ncbi.nlm.nih.gov/ pubmed/17441542

23. Statistics Canada: Canadian Community Health Survey Annual Component (CCHS). https://www.statcan.gc.ca/eng/ survey/household/3226 (2015). Accessed 15 Jan 2018

24. Statistics Canada: Ongoing. Canadian Health Measures Survey. http://www.statcan.gc.ca/eng/survey/household/5071 (Ongoing). Accessed 14 Nov 2017

25. Bittar, R.S.M., Oiticia, J., Bottino, M.A., Ganança, F.F., Dimitrov, R.: Population epidemiological study on the prevalence of dizziness in the city of São Paulo. Braz. J. Otorhinolaryngol. 79(6), 688-698 (2013). https://doi.org/10.5935/1808-8694.20130127

26. Agresti, A.: Categorical Data Analysis (PDF), pp. 231-232. Wiley, Hooken (2002). ISBN 0-471-36093-7

27. Public Service Commission of Wisconsin (PSCW): Application of Highland Wind Farm, LLC, for a certificate of public convenience and necessity to construct a $102.5 \mathrm{MW}$ wind electric generation facility and associated electric facilities, to be located in the towns of Forest and Cylon, St. Croix County, Wisconsin. Final Decision on Remand. http://apps.psc.wi.gov/vs2015/ERF_ view/viewdoc.aspx?docid=290039 (2016). Accessed 14 Nov 2017 